\title{
PROCESSOS DE PRODUÇÃO DAS ELITES ESCOLARES
}

\author{
ZAIA BRANDÃO* \\ Cynthia PAES DE CARVAlHo**
}

\begin{abstract}
RESUMO: O texto traz a síntese de uma trajetória de mais de 10 anos de pesquisa em sociologia da educação. Após uma breve contextualização e descrição do programa de pesquisas desenvolvido, são apresentados os principais resultados e desafios enfrentados no processo de investigação no período, assim como os caminhos tomados para enfrentá-los. O foco principal dos esforços de investigação é a formação das elites escolares, inspirado nos estudos desenvolvidos por Pierre Bourdieu. As pesquisas foram desenvolvidas utilizando tanto métodos qualitativos como quantitativos, construindo uma perspectiva global de análise. Este percurso tem favorecido uma compreensão mais densa dos processos escolares e dos diferentes agentes envolvidos na produção das elites escolares, tanto nos sistemas públicos de ensino como na rede privada.
\end{abstract}

Palavras-chave: Sociologia da educação. Pesquisa. Elites escolares.

\section{Processes THAT LEAD TO THE PRODUCTION OF ACADEMIC ELITES}

ABSTRACT: This text presents a synthesis of 10 years of research in sociology of education. After a brief contextualization and description of the program developed, it presents the main results, the challenges faced along the way, and the means to overcome them. Research efforts focused on the creation of academic elites, in the wake of Bourdieu. Based on both quantitative and qualitative methods, they sought to build a global perspective of analysis. This approach helped to better understand the schooling processes and the different agents involved in the creation of elites in both public and private schools.

Key words: Sociology of education. Research. School elites.

* Doutora em Educação e professora titular do Departamento de Educação da Pontifícia Universidade Católica do Rio de Janeiro (PUC-Rio). E-mail: zaiapucrio@gmail.com.

* Doutora em Educação, pesquisadora e professora assistente do Departamento de Educação da Pontifícia Universidade Católica do Rio de Janeiro (puc-Rio).

E-mail: cynthiapaesdecarvalho@puc-rio.br 


\section{Processus de PRODUCTION DES ÉLITES SCOLAIRES}

RÉSUMÉ: Ce texte constitue une synthèse de plus de 10 ans de recherche en sociologie de l'éducation. Après une brève contextualisation et description du programme de recherches développé, il présente les principaux résultats, les difficultés qui ont surgi en cours de route et les solutions ayant permis de les surmonter. Inspirés par les travaux de Pierre Bourdieu, nos efforts de recherche se sont concentrés sur la production des élites scolaires. Des méthodes qualitatives et quantitatives nous ont aidés à construire une perspective globale d'analyse qui a permis une compréhension plus dense des processus scolaires et des différents agents impliqués dans la production d'élites scolaires dans l'enseignement public et privé.

Mots-clés: Sociologie de l'éducation. Recherche. Élites scolaires.

\section{Introdução}

$\mathrm{D}$

urante toda a segunda metade do século $\mathrm{xx}$, os processos de democratização do ensino foram os objetos de investigação privilegiados pela sociologia da educação. Analistas e pesquisadores brasileiros têm focalizado, sobretudo, as dificuldades das escolas responderem adequadamente às necessidades dos novos estratos das camadas populares, crescentemente incorporados ao sistema público de ensino em decorrência da ampliação das vagas. Entre as barreiras a um processo de escolarização bem sucedido estariam: (1) a distância entre os códigos linguísticos da escola (balizados na norma culta) e os códigos linguísticos das crianças, adquiridos em seu meio social, cuja suposta deficiência daria origem às hipóteses dos déficits linguísticos; (2) as condições e estilos de vida entre os estratos populares, distantes dos valores e das práticas socioculturais das camadas médias (cuja socialização primária seria mais congruente com a socialização escolar), que se mostravam inadequadas às exigências da escolarização e, por isso, deram origem à hipótese das carências culturais da população recém chegada à escola.

As questões da cultura popular e da linguagem foram tematizadas de forma emblemática por Paulo Freire na perspectiva da alfabetização dos adultos. A relação entre a linguagem e a experiência social (cotidiano, valores, simbolização e pautas culturais) era afirmada como ponto de partida fundamental para o êxito do processo de alfabetização. Esvaziadas de significado, as "cartilhas" utilizadas para a alfabetização nada mais eram do que um conjunto de fonemas isolados e opacos à sensibilidade dos analfabetos. O "método Paulo Freire" (Brandão, 1981), cujo sucesso foi sobejamente reconhecido, tornou-se um testemunho empírico inquestionável da necessidade de se rever a hipótese do déficit linguístico como causa do insucesso escolar das camadas populares.

No campo internacional, Bernstein (1979) destacou-se com a teoria dos códigos linguísticos, que deu origem a um relevante debate no campo da sociolinguística 
(Lawton, 1979) com desdobramentos importantes sobre a crítica à educação compensatória, ${ }^{1}$ cuja justificativa se ancorava na teoria dos códigos linguísticos de Bernstein.

Em meados da década de 1970, a obra Educação e desenvolvimento social no Brasil, de Luiz Antônio Cunha, delimitou um marco no campo da Sociologia da Educação, ao analisar os impasses da escolaridade no país, em meio ao "milagre brasileiro" 2 durante o regime militar instaurado em 1964. Nas décadas seguintes, multiplicaram-se as pesquisas e análises sobre as condições de uma democratização do ensino que, para além do acesso à escola, garantisse a permanência dos setores populares no sistema escolar com efetivo aproveitamento em termos de aprendizagem. $O$ fracasso escolar, a marginalização da cultura popular pelos currículos, as diferenças linguísticas e culturais, bem como os impactos das condições de vida sobre a escolarização foram alguns dos temas recorrentemente tratados pela pesquisa em educação.

A baixa escolaridade da população brasileira e a precariedade da educação fundamental no país mobilizavam, e ainda mobilizam, os pesquisadores na tentativa de oferecer subsídios às políticas educacionais. Neste contexto, a escolarização das elites ficou à sombra durante o período em que a Sociologia da Educação firmou-se como um campo de investigação no meio acadêmico brasileiro.

Pierre Bourdieu certamente foi o autor que, com sua vasta e inovadora obra, chamou a atenção para o que ocorria no polo oposto da sociedade, ou seja: como se constituíam as bases do sucesso escolar entre as camadas que se situavam nos patamares superiores da estratificação social. Depois dos Les étudiens et leurs études (1964), Les héritiers (1964) e La reproduction (1970), em coautoria com J.C. Passeron), a Sociologia da Educação nunca mais foi a mesma. Embora o papel atribuído por Bourdieu à escola tenha motivado a ampliação da pesquisa empírica sobre os processos de escolarização, a investigação sobre a escolarização das elites permaneceu, até a segunda metade da década de 1990, um tema tabu entre os pesquisadores brasileiros.

A coletânea A escolarização das elites, de Ana Maria Almeida e Maria Alice Nogueira, chama a atenção - de forma pioneira entre nós - para a pertinência da investigação sobre as práticas e estratégias das elites em relação à escolarização de seus filhos, para a compreensão dos processos de produção de "qualidade do ensino" numa perspectiva relacional, como propõe Bourdieu. As aspas em torno da expressão qualidade de ensino apontam para a necessidade de relativizar esta noção, uma vez que diversas pesquisas nacionais e internacionais (Nogueira, Romanelli \& Zago, 2000; Nogueira, 2004; Paes de Carvalho, 2006; Ballion, 1977; entre outros) têm mostrado que o sucesso da escolarização das elites muitas vezes se dá por estratégias de "evitamento" de fracasso através de escolhas mais adequadas, tais como a transferência para escolas menos exigentes a fim de prevenir prováveis reprovações, 
apoio escolar através de professores particulares, estágios no estrangeiro etc. Além disso, é preciso não esquecer que as escolas de maior prestígio frequentadas por estes grupos sociais costumam ser extremamente seletivas, quer no momento da matrícula inicial dos alunos, quer através de diferentes processos de seletividade interna - negociados com as famílias -, quando a reprovação tende a levar muitos alunos a procurar outras alternativas de escolarização (Mandelert, 2010).

\section{Da escolarização das elites à produção das elites escolares}

Após uma longa história de pesquisas sobre a democratização do ensino e a escolarização das camadas populares (Brandão, 1979a; 1979b; 1982; Brandão \& Kramer, 1981; e Brandão, Baeta \& Dutra, 1983), foi criado o grupo de pesquisas em Sociologia da Educação, que no final da década de 1990 desenvolveu sua primeira investigação sobre os processos de escolarização dos filhos das elites acadêmicas. Em direção contrária à hipótese inicial - de que os filhos desses acadêmicos seriam escolarizados nas mais prestigiosas escolas da cidade -, os resultados do survey ${ }^{3}$ evidenciaram uma enorme dispersão dos seus filhos em escolas privadas menos conhecidas e apenas um número reduzido deles matriculado em escolas públicas e privadas de maior prestígio (Brandão \& Lelis, 2003).

Tomando este resultado como um desafio de pesquisa, desenvolvemos um novo esforço de investigação, focalizando as características institucionais e familiares que interagiam na produção da imagem de qualidade de ensino de nove escolas, que há vários anos eram citadas pela imprensa como as melhores do município do Rio de Janeiro no período 2002 a 2004. ${ }^{4}$ Na seleção das escolas procuramos incluir diversos tipos de proposta pedagógica (bilíngues, confessionais, colégios de aplicação etc.), ultrapassando a clássica divisão públicas/privadas, como estratégia para pesquisar os perfis das famílias e estudantes que frequentavam estas escolas, cujos variados modelos pedagógicos potencialmente atrairiam diferentes tipos de elites (intelectuais, econômicas, artísticas, políticas etc.).

Se a análise dos dados do survey apontou variações pequenas em grande quantidade de variáveis relativas ao perfil das famílias, alunos e professores, o contato com as diversas escolas no decorrer da aplicação dos questionários e, posteriormente, no retorno com os resultados mostrou contextos institucionais distintos - inclusive na interlocução com os pesquisadores e na recepção da investigação. Essa diferença de percepção entre observação in loco e através de dados quantitativos suscitou a reflexão sobre a maneira como as diversas características institucionais dos estabelecimentos interagiam com o perfil dos respondentes dos questionários e engendrariam processos de produção de qualidade de ensino diferenciados em alguma medida. 
A preocupação com as condições em que as escolas podem fazer diferença já faz parte, há algum tempo, da agenda de equipes de pesquisadores em diversos países (Bressoux, 1994; Damiani, 1999; Cousin, 1998 e 2000; Canário, 1996; entre outros) nos fez também optar por um olhar mais detalhado sobre o cotidiano das escolas e os processos organizacionais e pedagógicos que articulavam os agentes escolares, produzindo padrões de distinção escolar com vistas à reprodução da qualidade do ensino ministrado e de seu reconhecimento junto à clientela. Entre nós, Albernaz, Ferreira \& Franco (2002, p. 3-4), trabalhando com microdados do Sistema de Avaliação da Educação Básica (SAEB), referentes a estudantes das oitavas séries, assinalaram:

Entre os resultados encontrados, destacamos três. Primeiro, como em outros países, a variância em desempenho entre as escolas brasileiras deve-se principalmente a diferenças no nível sócio-econômico médio de seus alunos, refletindo um importante efeito de seleção da clientela. Segundo, uma vez controlado este efeito, diferenças na quantidade $e$ qualidade dos insumos escolares ainda respondem por uma parcela significativa da diferença de desempenho entre as escolas. Ao contrário de resultados encontrados para vários outros países, tanto a qualidade dos professores quanto a qualidade da infraestrutura física das escolas afetam o rendimento de forma significativa. Terceiro, mesmo controlando para todos os fatores acima, no Brasil, o desempenho médio da escola particular supera o da escola pública. (Grifos nossos)

Tais reflexões inspiraram o desenho de uma nova etapa de investigação de caráter qualitativo ${ }^{5}$ desafiada pela perspectiva da aproximação das lentes às configurações específicas dos processos de escolarização das elites das escolas investigadas. Privilegiamos uma perspectiva interacionista (Paes de Carvalho, Lacerda \& Braga, 2007) para observar o cotidiano escolar e, particularmente, as salas de aula, focalizando o ambiente institucional e os fatores a ele correlatos que poderiam contribuir para o processo de produção da qualidade de ensino em cada estabelecimento. Para isso, selecionamos três escolas, considerando sua diversidade dentro da tipologia que serviu à definição de nossa amostra inicial (uma pública, uma confessional e uma alternativa) e a disponibilidade/abertura institucional para a continuação da pesquisa, sem perder de vista a necessidade de problematizar as tipologias escolares (Paes de Carvalho, 2006), incluindo a utilizada neste desenho de pesquisa.

No recorte que escolhemos para investigar - estratos médios e altos da sociedade -, no entanto, considerando a reconhecida centralidade do background familiar no desempenho escolar, tomamos como hipótese inicial que a imagem de qualidade das escolas de prestígio se apoiaria fundamentalmente na estrutura de capitais de sua clientela. Nesta perspectiva, o efeito-escola sobre os resultados dos estudantes destas camadas sociais seria bem menor do que o prestígio das escolas permitiria supor.

Embora não constassem de nossa pesquisa medidas de proficiência, o material empírico produzido - quer pelo survey, quer pelo trabalho de campo com observações sobre o cotidiano escolar e entrevistas com os diferentes agentes envolvidos em três 
destas escolas - apontou para a mesma direção dos autores citados: os fatores escolares teriam um peso bem maior no bom desempenho dessas escolas do que supúnhamos inicialmente.

\section{Tomadas de cena de um mesmo problema}

Nossas investigações têm procurado alternar um olhar mais abrangente (survey) com um mais próximo (entrevistas e observações de campo), na convicção de que, com essas diferentes "tomadas de cena", desenvolvemos recortes complementares e, consequentemente, mais compatíveis com o caráter complexo dos fenômenos estudados no campo da Sociologia da Educação. Qualquer desses enfoques, entretanto, quando tomados isoladamente, oferece uma perspectiva limitada dos fenômenos sociais (Brandão, 2000).

Randall Collins (2000), preocupado com o estatuto de realidade objetiva normalmente atribuído aos levantamentos estatísticos derivados de surveys, examina inúmeras situações em que opções iguais de respostas a questionários têm significados bastante distintos, segundo os distintos respondentes, em virtude da "estratificação situacional" dos agentes investigados. Para produzir uma interpretação adequada dos dados gerados por surveys, tais variações precisam ser levadas em conta. De acordo com este autor, exemplos típicos desta ilusão de objetividade seriam as hierarquias desenhadas pela distribuição dos grupos em categorias ocupacionais, categorias estas que podem ocultar diferenças importantes de riqueza, educação e prestígio que impactam os problemas em investigação. Nas palavras de Collins (op. cit., p. 18), “(...) estatísticas globais e dados de surveys não oferecem um retrato acurado da realidade social, a não ser quando interpretados no contexto de seu enraizamento micro-situacional".

Nossa experiência de pesquisa com surveys e entrevistas tem evidenciado a pertinência deste alerta. ${ }^{6}$ Frente à indagação sobre $o$ que a escola deve propiciar aos alunos, por exemplo, pode-se encontrar significados e ênfases muito diferentes sob os rótulos qualidade acadêmica, espírito crítico... Da mesma forma, em questões referentes ao acompanhamento parental dos estudos dos filhos, a mesma resposta "acompanho diariamente os estudos do meu filho" pode significar formas de acompanhamento muito diversas: desde pais que acompanham e ajudam a fazer as tarefas escolares, até os que simplesmente definem um horário diário para que eles façam os deveres de casa.

As estratégias de pesquisa e os instrumentos construídos nestes últimos cinco anos - questionários, grades de observação, roteiros de entrevistas, registros de campo, categorias de análise etc. - têm sido sistematicamente reavaliados tanto em seus aspectos positivos, como em suas insuficiências, imprecisões e até mesmo equívo$\cos ^{7}$ Confrontamo-nos, permanentemente, com a necessidade de ampliar o campo de 
nossas referências, reformular hipóteses teóricas, precisar a terminologia $a^{8}$ e os conceitos com que trabalhamos, assim como desenvolver novas interlocuções para incrementar a construção de estratégias mais adequadas aos desafios postos pelo processo de investigação.

\section{Alguns resultados da investigação}

O programa de investigação no campo da Sociologia da Educação tem recorrido tanto ao survey como a modalidades mais qualitativas de pesquisa através da observação do cotidiano escolar e das salas de aula, de entrevistas com pais, professores e alunos, assim como de grupos focais com os agentes escolares. Basicamente, temos estudado as séries finais do ensino fundamental, em particular a 8 a série ou $9^{\circ}$ ano em escolas públicas e privadas reconhecidas pela qualidade do ensino ministrado. Além do primeiro survey junto a professores universitários, realizamos outros dois (2002-2004 e 2009-2010) compostos de questionários aplicados a pais, professores e alunos da $8^{\mathrm{a}}$ série $/ 9^{\circ}$ ano do ensino fundamental.

A síntese apresentada a seguir refere-se aos resultados do survey que realizamos entre 2002 e 2004 em nove escolas de grande prestígio na cidade do Rio de Janeiro (duas confessionais, duas bilíngues, duas alternativas, duas públicas federais e uma escola judaica).

\section{Circularidade virtuosa}

Após a análise dos dados produzidos pelo survey realizado em 2002-2004, um primeiro balanço levou-nos a reafirmar a circularidade virtuosa (Brandão, Mandelert \& Paula, 2005) produzida pela articulação dos perfis das famílias e estudantes com a qualidade e experiência dos profissionais integradas no projeto político-pedagógico das escolas investigadas. Além da estrutura e do volume de capitais favoráveis às exigências da escolaridade nestas instituições, os aspectos de gestão pedagógico-administrativa, a qualidade da formação e a experiência dos docentes, assim como as condições de trabalho, funcionam como fatores facilitadores do bom desempenho dos alunos, que lastreiam a projeção de uma imagem de qualidade destas escolas.

\section{Mudanças nos perfis de capital cultural das elites}

As transformações no plano cultural, que têm levado à quebra dos padrões de legitimidade que serviam a uma hierarquização dos gostos culturais - entre cultura erudita e cultura popular, por exemplo -, já têm sido amplamente analisadas no campo das Ciências Sociais. ${ }^{9}$ Entretanto, no campo escolar ainda se encontram parâmetros tradicionais de legitimidade cultural que se estendem dos conhecimentos disciplinares 
até os gostos e práticas culturais. Os questionários do survey que realizamos em 2002 e 2004 procuraram elencar um espectro amplo dessas práticas, objetivando categorizar estilos e gostos diferenciais dos públicos das escolas investigadas.

A análise dos resultados mostrou que práticas culturais próprias do que se convencionou tradicionalmente como de "alta cultura" não estavam representadas, senão excepcionalmente, entre os sujeitos investigados. A "cultura das saídas" (Ortiz, 2000) - como idas a shoppings, restaurantes, viagens de fim de semana, programas sociais com amigos e familiares - evidenciou-se como uma prática muito frequente entre os sujeitos investigados. Da mesma forma, o uso intensivo de canais de informação (leitura diária de jornais, assinatura de revistas informativas e telejornais e programas de entrevistas e debates) indicava um alto volume de capital informacional (Brandão \& Martinez, 2006), que compunha o núcleo duro das práticas culturais modais deste público.

\section{Novos estilos cognitivos dos jovens estudantes}

As respostas - muitas vezes pertinentes - dadas pelos alunos aparentemente mais dispersos e agitados ("alunos desatentos") às frequentes demandas dos professores feitas, especialmente, àqueles que se encontravam dispersos durante as aulas observadas no trabalho de campo, levaram a equipe a reavaliar o conceito de atenção que guiava as observações. Formulamos então a hipótese da presença de "novos estilos de cognição" entre os estudantes (Brandão, 2005), o que, por sua vez, tem encontrado respaldo na bibliografia que vem focalizando a utilização crescente pela juventude das tecnologias de informação e comunicação.

\section{Delegação da educação dos filhos às escolas}

Uma das "observações" mais recorrentes entre os agentes escolares, nas nove instituições investigadas entre 2002 e 2007, foi a de que cada vez mais as famílias tendem a delegar à escola o controle do comportamento dos filhos. Em algumas das escolas, as "explicações" acionadas pelos professores e gestores referiam-se a maior inserção das mães no mercado de trabalho e à liberdade precoce dos jovens estudantes que, sem supervisão familiar, levariam à falta de limites observada no comportamento de muitos alunos no ambiente escolar.

\section{Gestão pedagógico-administrativa, controle curricular e monitoramento dos alunos}

Identificamos estilos de gestão - de caráter matricial, estruturados a partir de várias linhas de interação verticais e horizontais, que multiplicam momentos 
de supervisão, controle e monitoramento do trabalho pedagógico - que facilitam o acompanhamento permanente do trabalho desenvolvido pela instituição, sustentando estratégias de controle e apoio aos estudantes (Paes de Carvalho \& Canedo, 2008).

\section{Pluralidade dos estilos docentes e autonomia nas salas de aula}

Embora este seja um tema já bastante abordado pela literatura educacional, nossa investigação apontou para a necessidade de explorar melhor como se combinam estilos de gestão pedagógico-administrativa com a autonomia docente em sala de aula. Temos observado que, ainda que os professores contem com considerável autonomia no trabalho docente, as escolas investigadas desenvolvem sistemas de supervisão e coordenação que parecem estruturar um estilo pedagógico - ou alguns parâmetros de qualificação do trabalho com os alunos - que atravessa as diferentes práticas e estilos docentes individuais. Cria-se dessa forma um "sentido do jogo", na perspectiva de Bourdieu (1979 e 1989), que comporta simultaneamente flexibilidade e unidade, compondo as identidades institucionais. A pluralidade de estilos docentes observada nas salas de aula, por sua vez, motiva-nos a tentar associar estilos docentes e campos disciplinares, numa tentativa de verificar se haveriam estilos docentes característicos de determinados campos disciplinares ou não.

\section{Senso de pertencimento}

Um dos dados mais recorrentes de nossa pesquisa foi o forte senso de pertencimento que atravessa os diferentes agentes escolares (alunos, professores, funcionários) nas instituições investigadas (Medeiros, 2006; Galvão, 2009). Expressão do capital simbólico das instituições de prestígio, esta questão é um dos eixos a partir do qual pretendemos aprofundar o conhecimento das estratégias de construção e transmissão de imagens institucionais que ligam, há várias décadas, gerações de alunos e docentes e constituem-se fontes importantes de fluxos de capital social e simbólico.

\section{Valorização da leitura}

Esta foi uma constante em todas as instituições investigadas. Entrevistas com bibliotecárias e professores, bem como a observação das bibliotecas escolares evidenciaram a valorização destes profissionais e os recursos empregados na atualização e renovação do acervo das escolas investigadas. Os dados sobre as relações dos jovens com a leitura, por sua vez, vão na direção oposta do que costuma ser apregoado pelo senso comum e reforçado pela mídia, que costuma realçar seu desinteresse por esta atividade (Xavier, 2009). 


\section{Famílias entre a sinergia e a distância}

Embora os "contratos de sucesso escolar" (Paes de Carvalho \& Lacerda, 2007) impliquem uma sintonia entre as escolas e as famílias, a interação pais/professores se desenvolve sob efetivo controle da instituição. De uma maneira geral, estabelecese uma espécie de "barreira" entre as famílias e os professores, que impede uma intervenção mais direta das famílias sobre as práticas pedagógicas desenvolvidas nas escolas. Em alguns casos, como o de uma das escolas públicas onde se desenvolveu o trabalho de campo, observou-se um consenso entre os gestores e professores no sentido de não mobilizar as famílias para resolver problemas escolares dos filhos, pois à escola caberia assumir integralmente a função de garantir as boas condições de escolarização aos seus estudantes (Medeiros, 2006). Porém, na maioria dos casos, as escolas parecem procurar preservar o seu nicho de competência técnica das intervenções familiares, muitas vezes impregnadas de casuísmos.

\section{Luta concorrencial pela manutenção do prestígio escolar}

Desde o início da investigação, chamou-nos a atenção o crescente investimento de algumas das instituições investigadas em suas páginas (sites) na internet. Algumas delas, que no início da pesquisa estavam com as suas páginas desatualizadas, empreenderam atualizações e modificações, num claro esforço em transmitir uma imagem do que as distingue no campo da oferta escolar. Algumas destas escolas, que se posicionaram mal nos rankings divulgados pela imprensa sobre os resultados do Exame Nacional do Ensino Médio (ENEM), de 2006, encaminharam diretamente aos pais, ou divulgaram em seus sites, argumentos em que destacavam as características que as diferenciavam no elenco das melhores instituições, e que não foram levadas em conta, em virtude dos parâmetros utilizados pelos sistemas de avaliação oficial. Diferenciarse se torna uma estratégia fundamental entre as escolas que disputam a preferência dos estudantes bem equipados para garantir a sua posição no pódio das melhores.

Continuamos desenvolvendo nosso programa de pesquisas, formando novos pesquisadores e aprendendo com os novos desafios que se apresentam a cada passo.

\section{Novos desafios}

Para o projeto de pesquisa em andamento (2008-2011) resolvemos realizar um novo survey, redesenhando nossos instrumentos com vistas a focalizar melhor as estratégias institucionais de desenvolvimento de habitus escolares e os estilos de gestão pedagógica, sem perder de vista o interesse em garantir certo grau de comparabilidade dos dados que compõem o corpus do programa de pesquisas. Além disso, pela primeira vez, incorporamos à amostra também escolas municipais, mantendo 
a perspectiva de estudar aquelas com reconhecida qualidade do ensino e do olhar sobre a $8^{\mathrm{a}}$ série $/ 9^{\mathrm{o}}$ ano do ensino fundamental. Para isso, utilizarmos os resultados da "Prova Brasil" de 2005 e 2007 na seleção das escolas da rede municipal, e os resultados do ENEM $(2005,2006$ e 2007) na seleção das escolas da rede privada (Paes de Carvalho, Felipe \& Mandelert, 2011). Assim como na etapa anterior, previmos também uma incursão mais qualitativa no campo em algumas destas escolas, após a análise exploratória dos resultados do survey.

Ao incluir neste novo esforço de pesquisa algumas das melhores escolas municipais do Rio de Janeiro, pretendemos levantar hipóteses empiricamente fundamentadas sobre o "efeito-escola" na produção do sucesso escolar entre setores também nas camadas populares. A análise exploratória dos dados deste novo survey (2009-2010) já vem apontando para a perspectiva de estudar também mais detidamente as diferentes formas e estilos de gestão, focalizando, sobretudo, a dimensão do monitoramento institucional em sua articulação com a gestão das relações com o corpo docente e com as famílias. Acreditamos que esta será uma perspectiva fértil de investigação na direção do aprofundamento da análise do "efeito-escola", fundamental para a interpretação dos processos de produção da qualidade de ensino.

O recorte mais delimitado sobre o escolar na escola e da escola - num esforço de mapear e interpretar as estratégias institucionais que levariam à aquisição de habitus favoráveis ao bom desempenho escolar - tem nos desafiado a ampliar as referências, bem como a rever as estratégias de investigação e a construir instrumentos de pesquisa mais afinados com os problemas focalizados. Além de uma releitura de alguns dos trabalhos de Bourdieu, através do índice remissivo relativo às categorias mais pertinentes ao novo recorte, uma exploração bibliográfica inicial nos sugere a relevância, para além do conceito de habitus, dos conceitos de cultura escolar (Julia, 2001; Forquin, 1993), ofício do aluno (Lelis, 2005; Perrenoud, 1995; Sirota, 2000), socialização e sociabilidade (Dubar, 1995; Plaisance, 2004; Setton, 2005; Sirota, 2005) e forma escolar (Vincent, Lahire \& Thin, 2001). Neste movimento, optamos por mudar a terminologia - de escolarização das elites para produção das elites escolares -, expressando nossa necessidade de precisar melhor o foco da investigação, que agora se propõe, valendo-se da metáfora fotográfica, a utilizar um zoom sobre o trabalho escolar no desenvolvimento dos habitus dos alunos.

\section{Notas}

1. A centralidade da linguagem no debate sobre a democratização do ensino foi registrada, de forma pioneira, por Brandão (1979b) através da organização da coletânea, que incluía também textos de Lawton e Bernstein.

2. Expressão cunhada para indicar a notável expansão da economia brasileira entre 1968 e 1974 . O período conhecido como do "milagre brasileiro" foi uma alusão aos "milagres" alemão e japonês das décadas de 1950 e 1960. 
3. Encaminhado a todos os professores de uma das mais importantes universidades do Rio de Janeiro.

4. $\quad$ A pesquisa "Processos de produção de qualidade de ensino: escola, família e cultura" foi desenvolvida com apoio do CNPq e da FAPERJ.

5. Tratou-se da pesquisa: "Para além das homogeneidades - singularidades institucionais em processos de escolarização", desenvolvida em 2006/2007 também com apoio do cNPq e da FAPERJ.

6. No diferentes surveys que temos desenvolvido, discutimos intensamente sobre a qualidade dos dados produzidos como parte do processo de preparação da base de dados - através da leitura coletiva pela equipe de uma amostra dos questionários respondidos para avaliação das diferentes possibilidades de compreensão das questões.

7. Como o controle deficiente da distribuição dos questionários dos professores, no survey realizado na primeira pesquisa sobre escolas de prestígio, o que tornou imprecisa a representatividade dos mesmos nas diferentes escolas.

8. Optamos por utilizar a expressão "elites escolares" ao invés de "escolarização das elites", pois julgamos que a diversidade de instituições com as quais trabalhamos atingia não somente "elites", mas segmentos médios e populares que, através das trajetórias nessas escolas, acabam obtendo certificados escolares de elevado capital simbólico e social em nossa sociedade.

9. Entre eles, no Brasil e América Latina: Renato Ortiz, Nestor Canclini, Martin-Barbero e Maria da Graça Setton; na França: Olivier Donnat e Philippe Coulangeon; Nos EuA: Michele Lamont, Diana Crane e Hebert Gans.

\section{Referências}

ALBERNAZ, A.; FERREIRA, F.; FRANCO, C. A escola importa?: determinantes da eficiência e da equidade no ensino fundamental brasileiro. In: ENCONTRO SOBRE DETERMINANTES DO SUCESSO ESCOLAR. Atas do... Rio de Janeiro: IPEA, 2002.

ALMEIDA, A.M.F.; NOGUEIRA, M.A. (Org.). A escolarização das elites: um panorama internacional da pesquisa. Petrópolis: Vozes, 2002.

BALLION, R. L'argent et l'école. Paris: Pernoud; Stock, 1977.

BERNSTEIN, B. Uma crítica ao conceito de educação compensatória. In: BRANDÃo, Z. (Org.). Democratização do ensino: meta ou mito? Rio de Janeiro: Francisco Alves, 1979. p. 43-57.

BOURDIEU, P. La distintion. Paris: Minuit, 1979.

BOURDIEU, P. La noblesse de l' État. Paris: Minuit, 1989.

BOURDIEU P.; PASSERON J.C. Les héritiers: les étudiants et la culture. Paris: Minuit, 1964.

BOURDIEU, P.; PASSERON, J.C. La reproduction. Paris: Minuit, 1970.

BOURDIEU P.; PASSERON, J.C.; ELIARD, M. Les étudiants et leurs etudes. Paris: La Haie; Mouton, 1964. (Cahiers du Centre de Sociologie Européenne, 1). 
BRANDÃO, C.R. O que é método Paulo Freire. 18. ed. São Paulo, Brasiliense, 1981.

BRANDÃO, Z. Fracasso escolar e educação compensatória: considerações críticas. Revista de Educação, Juiz de Fora, v. 34, p. 19, 1979a.

BRANDÃO, Z. Democratização do ensino: meta ou mito? Rio de Janeiro: Francisco Alves, 1979b.

BRANDÃO, Z. A Formação dos professores e a questão da educação das crianças das camadas populares. Cadernos de Pesquisa, São Paulo, n. 40, p. 54-57, fev. 1982.

BRANDÃO, Z. Entre questionários e entrevistas. In: NogUeIRA, M.A.; RomanELli, G.; ZAGo, N. (Org.). Família e escola. Rio de Janeiro: Vozes, 2000. p. 171-183.

BRANDÃO, Z. Fluxos escolares e efeitos agregados pela escola. Em Aberto, Brasília, DF, v. 17, p. 41, 2000.

BRANDÃO, Z. A dialética micro/macro na Sociologia da Educação. Cadernos de Pesquisa, São Paulo, n. 113, p. 153-165, 2001.

BRANDÃO, Z. Clima escolar: notas de campo de três visitas a escolas. Boletim SOCED, n. 2, p. 1-19, 2005. Disponível em: <http://www.soced.pro.br>. Acesso em: 20 jun. 2009.

BRANDÃO, Z. Desatenção ou novos estilos de cognição? Boletim SOCED, n. 1, p. 1-8, 2005. Disponível em: <http://www.soced.pro.br>. Acesso em: 20 jun. 2009.

BRANDÃO, Z. Elites escolares e capital cultural. Boletim SOCED, n. 3, 2006. Disponível em: <http://www.soced.pro.br>. Acesso em: 20 jun. 2009.

BRANDÃO, Z. A produção das elites escolares. Educação On Line, Rio de Janeiro, n. 2, 2006.

BRANDÃO, Z.; ALTMAN, H. Algumas hipóteses sobre a transformação dos habitus. Boletim SOCED, n. 1, p. 1-12, 2005. Disponível em: <http://www.soced.pro.br>. Acesso em: 20 jun. 2009.

BRANDÃO, Z.; BAETA, A. M.; DUTRA, A. Evasão e repetência no Brasil: a escola em questão. Rio de Janeiro: Achiamé, 1983 [1982].

BRANDÃO, Z.; CARVALHO, C.; CAZELLI, S. A elite docente na produção da qualidade de ensino. Boletim SOCED, n. 1, p. 1-19, 2005. Disponível em: <http://www.soced. pro.br>. Acesso em: 20 jun. 2009.

BRANDÃO, Z.; KRAMER, S. O pré-escolar e as classes desfavorecidas. Cadernos de Pesquisa, São Paulo, n. 39, p. 43-45, nov. 1981. 
BRANDÃO, Z.; LACERDA, P.; PAES DE CARVALHO, C. Contracts of school success: a discussion of family-school relationships from a relational perspective. Montreal: ISA/RC28, 2007.

BRANDÃO, Z.; LELIS, I. Elites acadêmicas e escolarização dos filhos. Educação $\mathcal{E}$ Sociedade, Campinas, v. 83, n. 83, p. 509-526, 2003.

BRANDÃO, Z.; MANDELERT, D.; PAULA, L. A circularidade virtuosa: investigação sobre duas escolas no Rio de Janeiro. Cadernos de Pesquisa, São Paulo, v. 35, n. 126, p. 747-758, 2005.

BRANDÃO, Z.; MARTINEZ, M.E. Elites escolares e capital cultural. Boletim SOCED, n. 3, 2006. Disponível em: <http://www.soced.pro.br>. Acesso em: 20 jun. 2009.

BRANDÃO, Z.; VARGAS, H. Escola alternativa. Boletim SOCED, n. 3, 2006. Disponível em: <http://www.soced.pro.br>. Acesso em: 20 jun. 2009.

BRESSOUX, P. Les recherches sur les effets-écoles er les effets-maîtres. Revue Française de Pédagogie, Paris, n. 108, p. 91-137, juil./sept. 1994.

CANÁRIO, R. Os estudos sobre a escola: problemas e perspectivas. In: BARroso, J. (Org.). O estudo da escola. Porto: Porto, 1996. p. 125-150.

COLLINS, R. Situational stratification: a micro-macro theory of inequality. Sociological Theory, San Francisco, v. 18, n. 1, p. 16-43, 2000.

COUSIN, O. L'efficacité des collèges: sociologie de l'effet établissement. Paris: PuF, 1998.

COUSIN, O. Politiques et effets-établissements dans l'enseignement secondaire. In: VAn Zanten, A. (Dir.). L'école l'état des saviors. Paris: La découverte, 2000. p. 139-148.

CUNHA, L.A. Educação e desenvolvimento social no Brasil. Rio de Janeiro: Francisco Alves, 1975.

DAMIANI, M.F. Fracasso escolar na escola fundamental: da identificação de fatores de risco extra-escolares ao entendimento dos processos intra-escolares. In: REUNIÃO ANUAL DA ANPEd, 22., 1999, Caxambu. Anais... Caxambu, 1999.

DUBAR, C. La socialisation: construction des identités sociales e profissionnelles. 2. ed. Paris: A. Colin, 1995.

FARIA FILHO, L.M. et al. A cultura escolar como categoria de análise e como campo de investigação da história da educação brasileira. Educação \& Pesquisa, São Paulo, v. 30, n. 1, p. 139-159, jan./abr. 2004.

FORQUIN, J.C. Escola e cultura: as bases sociais e epistemológicas do conhecimento escolar. Porto Alegre: Artes Médicas, 1993. 
GALVÃO, M.C.S. Nós somos a História da Educação!: identidade institucional e excelência escolar no Colégio Pedro II. 2009. Tese (Doutorado) - Departamento de Educação, Pontifícia Universidade Católica do Rio de Janeiro, Rio de Janeiro.

JULIA, D. A cultura escolar como objeto histórico. Revista Brasileira de História da Educação, Campinas, n. 1, p. 9-44, 2001.

LAWTON, D. Pesquisas sobre as relações entre linguagem e escola. In: BRANDão, Z. (Org.). Democratização do ensino: meta ou mito? Rio de Janeiro: Francisco Alves, 1979. p. 25-42.

LELIS, I. O significado da experiência escolar para segmentos das camadas médias. Cadernos de Pesquisa, São Paulo, v. 35, n. 125, p. 137-160, maio/ago. 2005.

MANDELERT, D. Repetência em escolas de prestígio: quanto, quando e como acontecem. 2010. Tese (Doutorado) - Departamento de Educação, Pontifícia Universidade Católica do Rio de Janeiro, Rio de Janeiro.

MEDEIROS, V.G. O que faz uma escola como tantas outras, tão diferente de todas as outras: estudo de caso. 2006. Dissertação (Mestrado) - Departamento de Educação, Pontifícia Universidade Católica do Rio de Janeiro, Rio de Janeiro.

NOGUEIRA, M.A. Famílias de camadas médias e a escola: bases preliminares para um objeto em construção. Educação \& Realidade, Porto Alegre, v. 1, n. 20, p. 9-25, 1995.

NOGUEIRA, M.A. Relação família-escola: novo objeto na sociologia da educação Paidéia: Cadernos de Psicologia e Educação, Ribeirão Preto, v. 8, n. 14/15, p. 91-103, fev./ ago. 1998.

NOGUEIRA, M.A. Favorecimento econômico e excelência escolar: um mito em questão. Revista Brasileira de Educação, Rio de Janeiro, v. 26, n. 26, p. 133-184, 2004.

NOGUEIRA, M.A.; ROMANELLI, G.; ZAGO, N. (Org.). Família e escola: trajetórias de escolarização em camadas médias e populares. Petrópolis: Vozes, 2000.

ORTIZ, R. Mundialização e cultura. 2. ed. São Paulo: Braziliense, 2000.

PAES DE CARVALHO, C. Contextos institucionais e escolarização: uma hipótese de classificação das escolas da rede privada de educação básica. Revista Brasileira de Educação, Rio de Janeiro, v. 11, n. 31, p. 155-166, abr. 2006.

PAES DE CARVALHO, C.; CANEDO, M.L. Estilos de gestão em escolas de prestígio do Rio de Janeiro. Boletim SOCED, n. 6, 2008. Disponível em: <http://www.soced.pro. br>. Acesso em: 20 jun. 2009. 
PAES DE CARVALHO, C.; FELIPE, L.H.L.; MANDELERT, D. Uso de dados de avaliação para escolha de escolas para um survey: desafios para a imaginação e o rigor metodológico. Ensaio: Avaliação e Políticas Públicas em Educação, Rio de Janeiro, v. 19, n. 70, p. 127-148, jan./mar. 2011.

PAES DE CARVALHO, C.; LACERDA, P.M. Contratos de sucesso escolar: problematizando interpretações sobre a relação família-escola. In: ENCONTRO ANUAL DA ANPOCS, 31., Caxambu, 2007.

PAES DE CARVALHO, C.; LACERDA, P.; BRAGA, M.F. Voltando às escolas para olhar mais de perto. Boletim SOCED, n. 4, 2007. Disponível em: <http://www.soced.pro. br>. Acesso em: 20 jun. 2009.

PERRENOUD, P. Ofício de aluno e sentido do trabalho escolar. Porto: Porto, 1995.

PLAISANCE, E. Para uma sociologia da pequena infância. Educação \& Sociedade, Campinas, v. 25, n. 86, p. 221-241, abr. 2004.

SETTON, M.G.J. A particularidade do processo de socialização contemporânea. Tempo Social, São Paulo, v. 17, n. 2, p. 335-350, 2005.

SIROTA, R. Le métier d'éleve. In: Forquin, J.C. Sociologie de l'éducation: nouvelles approches, noveaux objets. Paris: INRP, 2000. p. 149-172.

SIROTA, R. Primeiros amigos: os aniversários da infância, dar e receber. Educação \& Sociedade, Campinas, v. 26, n. 91, p. 535-562, maio/ago. 2005.

VAN ZANTEN, A.; DEROUET, JL.; SIROTA, R. Abordagens etnográficas em sociologia da educação: escola e comunidade, estabelecimento escolar, sala de aula. In: Forquin, JC. Sociologia da Educação: dez anos de pesquisas. Petrópolis: Vozes, 1995 [1990]. p. 205-297.

VINCENT, G.; LAHIRE, B.; THIN, D. Sobre a história e teoria da forma escolar. Educação em Revista, Belo Horizonte, n. 33, p. 7-48, jun. 2001.

XAVIER, A.P. Elites escolares: gosto literário e hábitos de leitura. 2009. Dissertação (Mestrado) - Departamento de Educação, Pontifícia Universidade Católica do Rio de Janeiro, Rio de Janeiro.

Recebido em março de 2011.

Aprovado em maio de 2011. 